\title{
Nurses' Cyberloafing and Its Relationship to Procrastination and Conscientiousness in Damanhour National Medical Institute
}

\author{
Yaldez Khairy Zein El Din ${ }^{1,2, ~ *, ~ F a t m a ~ M o s t a f a ~ B a d d a r ~}{ }^{3,4}$ \\ ${ }^{1}$ Nursing Administration Department, Faculty of Nursing, The British University in Egypt (BUE), Cairo, Egypt \\ ${ }^{2}$ Nursing Administration Department, Faculty of Nursing, Damanhour University, Damanhour, Egypt \\ ${ }^{3}$ Nursing Administration and Education Department, College of Nursing, King Saud University, Al Riyadh, Kingdom of Saudi Arabia \\ ${ }^{4}$ Nursing Administration Department, Faculty of Nursing, Alexandria University, Alexandria, Egypt
}

Email address:

yaldez.zeineldin $a$ bue.edu.eg (Y. K. Z. El Din), fbadar $a$ ksu.edu.sa (F. M. Baddar)

${ }^{*}$ Corresponding author

\section{To cite this article:}

Yaldez Khairy Zein El Din, Fatma Mostafa Baddar. Nurses' Cyberloafing and Its Relationship to Procrastination and Conscientiousness in Damanhour National Medical Institute. American Journal of Nursing Science. Vol. 8, No. 2, 2019, pp. 48-58.

doi: 10.11648/j.ajns.20190802.13

Received: February 10, 2019; Accepted: March 11, 2019; Published: March 25, 2019

\begin{abstract}
Cyber-loafing involves an unproductive use of time in the workplace and distracts employees from their responsibilities and duties. This study was conducted because there is a risk posed on patient's safety if nurses are cyberloafing and if this behavior has a direct relation with procrastination and lack of conscientiousness. Aim of the study: to determine the relationship between cyberloafing, procrastination and conscientiousness among staff nurses working in Damanhour National Medical Institute. Research Design: A cross-sectional descriptive correlational design with a self-reporting questionnaire was used to obtain data. Setting: The study was conducted in all inpatients units except Intensive Care Units $(\mathrm{N}=10)$ in Damanhour National Medical Institute. Subjects: A convenience sampling technique was used to recruit the participants of 157 (professional and technical nurses) were present and agreed to participate in the study. Instruments: The questionnaire consisted of three main scales and a demographic data sheet. The scales were namely; cyberloafing scale, procrastination scale, and conscientiousness scale. Results: There are significant correlations between cyberloafing variety and cyberloafing frequency, procrastination and conscientiousness where $p=<0.001$ for the three variables respectively. Regarding, cyberloafing frequency, a negative significant correlation was found with procrastination where $p=<0.001$ and a positive significant correlation with conscientiousness where $\mathrm{p}=0.048$. Another positive significant correlation was found between procrastination and conscientiousness in which $\mathrm{p}=<0.001$. Recommendations: more extensive and in-depth research on procrastination and conscientiousness in a private sector, where there is more availability of personal computer and internet connections would be beneficial.
\end{abstract}

Keywords: Cyberloafing, Cyberslacking, Personal Use of Computer, Procrastination Among Nurses, Conscientiousness

\section{Introduction}

Nowadays, cyberloafing is considered one of the practices that is highly noticed among employees in different workplaces, also it has grasped the attention of many employers worldwide. Furthermore, cybetrlaofing remains an evolving topic among different academic disciplines [1]. Cyberloafing has been defined as the personal usage of internet separately from tasks of employees in job environment [2-4]. Lim \& Teo (2005) viewed cyberloafing as a practice of workplace nonconformity because it involves an unproductive use of time in the workplace and distracts employees from their responsibilities and duties [2, 5]. Despite the interest of the academics and business to study cyberloafing and its consequences on the organization's productivity, still there is no clear line what constitutes cyberloafing behaviors [6-7]. Many organizational factors are 
found to contribute to the employees' cyberloafing behaviors, for instance; the presence of company policy to use the internet and the mechanism to monitor employees while working [6, 8-9].

In health care sectors, it is totally different to conduct a cyberloafing behavior through using personal communication devices (smart phones, tablets) while providing nursing care to the patients. Many benefits have been recorded of having a personal communication device that could connect nurses to the internet for example; access to medical references and patient information, it could also be used for documentation, patient education and consultation. Furthermore, in today's electronic worlds there are many applications that have been created for different medical specialties [10-16]. On the other hand, the distractions that can occur while using personal communication devices and lead to substandard nursing practices should be put into consideration while permitting these devices in the workplace [17-18].

Many concerns had upraised all over the world about the use of clinicians of personal communication devices during providing care. Currently, an ever-increasing diverse number of recreational sites are available such as social networking and games applications. Several research found that it is common among the majority of workers to conduct cyberloafing behavior during working hours unrelatedly to their positions or occupational status or even their age groups [19-23]. Patterson (2012) reported that operating rooms managers complained from clinicians' distraction during work due to use of personal communication devices in nonwork related activities [24]. Furthermore, an annual top tentechnology hazards report was issued by the Emergency Care Research Institute (ECRI) and ranked the "Caregiver distractions from smartphones and other mobile devices" the ninth hazard [25]. Moreover, the American Nurses Association Anesthetists (ANAA; 2013) also issued a position statement denoting that the use of personal communication devices during working will be considered a potential patients' safety issues [26].

Different international nursing association discussed unlike issues related to using personal communication devices while working. For instance, The American Nurses Association (ANA) included social media in their code of ethics [27]. Furthermore, a book published in 2011 by the honorary nursing association Sigma Theta Tau, which specified one chapter to elaborate guidelines on problems associated with the use of electronic media [28]. Also, United Kingdom Royal College of Nursing drafted some recommendations on using electronic media appropriately [29], and finally Canada issued legal advice on nurses' use of electronic media from a regulatory perspective [30]. As the Internet is often described as entertaining and interesting, it is assumed a good distracter to enable procrastination [31]. Furthermore, it had been proven from many researches that using internet and social medias e.g. facebook, twitter etc. Are leading causes to procrastination and delay in performing required duties [32-35]. According to The Ottawa Citizen (2008), there is an increase of procrastination caused by technology from $5 \%$ to $25 \%$ in recent years, recommending that an analysis of the association between procrastination and cyberloafing is relevant and would contribute to researchers' understanding of these types of behaviors [36].

Steel describes procrastination as related with individual's neurobiology, in which long-term intentions can be overridden by impulses generated by the limbic system, which is particularly sensitive to stimuli that indicates immediate gratification [37]. Moreover, Kinsola et al defined procrastination as behavior, which contains many different components of behavioral, motivational and cognitive factors [38]. Procrastination also had been defined by Chu and Choi as the absence or lack of regular performance, and behavioral intention to postpone what is necessary for the purpose [39].

Kinsola et al. [38] stated many actions included with procrastination such as indecision, fear of failure, job conflict, impulsivity, risk taking and rebellion. Procrastination had been evaluated usually to be a problem and linked to many negative consequences, for instance; inhibition of progression, lack of achievement, negative work outcomes as well as irreparable results [37].

More recent studies have searched specific topics, focusing on the association between procrastination and coping [40], and academic performance [41]. Also, Ferrari et al. [42] used the General Procrastination Scale developed by Lay [43] to examine behavioral delay and its relation to cyberloafing behavior. Procrastination has been studied extensively in the academic settings among students, yet studies of procrastination in different workplace including healthcare settings are very limited [44]. Furthermore, Steel [45] found that procrastinators are conceptually representative of low conscientiousness and self-regulatory failure. In addition to The Ottawa Citizen study [36] which stated that individuals who procrastinate are impulsive and lack conscientiousness.

Conscientiousness is known to be a personality trait which is composed of six parts, namely; achievement, dutifulness, competence, goal - striving, orderliness, self-discipline and deliberation as stated by Ferrari \& Pychyl [46-47]. Furthermore, Ehrenberg et al. defined conscientiousness to be an individual's ability to be careful and efficient which lead to improving task performance [48]. Other studies found that those who demonstrate high levels of trait conscientiousness are better performers than those who do not [49-50]. Conscientiousness has been known to be the strongest predictor of performance across multiple measures as stated by Neal et al. [51]. Also, Conscientiousness has been related to goal orientation after what was found by Westerman \& Simmon [52], as well as all nine indicators of performance framework as stated by Griffin et al. [53] work, with the most strongly predicted indicator from the nine is individual task proficiency being predicted after Neal et al's findings [51].

In nursing, the majority of study were conducted on conscientious objection [54-57].

A study done by Ehrenberg et al, 2008 found that nurses who are highly conscientious and work under time pressure may contribute to patient safety. On the other hand, nurses who have low conscientiousness level are possibly lacked 
of systematic, organized behavior and are usually irresponsible for patient care. [49]. Some research has been done to study the relationship between one part of conscientiousness and other variables. For instance, Orderliness has been linked to overall performance, task performance counterproductive workplace behaviors, interpersonal facilitation, interpersonal relations and task orientation as found by Dudley et al. [58]. Goal-striving has been linked to task performance, and counterproductive workplace behaviors. Also, dependability has been linked to overall performance, interpersonal facilitation, counterproductive workplace behaviors [58].

This study is significant because there is a risk posed on patient's safety if nurses are cyberloafing and if this behavior has a direct relation with procrastination and lack of conscientiousness. Hence, the study needed to guide the development of policies and guidelines about the use of personal communication devices while working. In this concern, Shehu and Salomon [59] prefer some rules or policies in order for organizational justice to prevail. However, Lim et al. [21] assert that when employees have strong locus of control and perhaps strong religious background, and conscientiousness then incidences of cyberloafing will be greatly reduced, procrastination will be avoided and productivity boosted as they consider the behavior as stealing from the employer.

\section{Materials and Methods}

\subsection{Materials}

\subsubsection{Aim of the Study}

The current study aims to determine the relationship between cyberloafing, procrastination and conscientiousness among staff nurses working in Damanhour National Medical Institute.

\subsubsection{Research Design}

A cross-sectional descriptive correlational design was used in this study to describe the variables and examine relationships among these variables.

\subsubsection{Research Questions}

1. What is the frequency of cyberloafing among study subjects?

2. What is the procrastination level among study subjects?

3. What is the level of conscientiousness among nurses?

4. Is there a relationship between cyberloafing, procrastination and conscientiousness among nurses?

\subsubsection{Setting}

The study was conducted in Damanhour National Medical Institute with bed capacity (336). Damanhour National Medical Institute is affiliated to General Organization for Teaching Hospitals and Institutions. It was established in 1963 and is considered one of the largest hospitals that serve El Boheira Governorate patients. The study included all inpatients units except Intensive Care Units, $(\mathrm{N}=10)$ namely;
1) Renal dialysis unit, 2) Surgical units with four sub-units (A general surgery, B cosmetic and ophthalmology unit, C oncology unit, D blood vessel surgery unit), 3) Ear, Nose and Throat (ENT) unit, 4) Urology unit, 5) Orthopedic unit, 6) Medical units with three sub-units (a) hepatic and cardio thorax unit, b) gastrointestinal unit GIT and C) Neuropsychiatric unit), 7) Hematemesis unit, 8) Nephrology unit, 9) Obstetrics unit, 10) Pediatrics unit.

\subsubsection{Subjects}

All professional and technical nurses who were present in the previously mentioned units during data collection and accepted to participate in the research were given the questionnaire. The study subjects were 157 out of total population $\mathrm{N}=270$.

Epi Info Program version 7 was used to estimate the sample size given that:

1. Population size $=270$

2. Expected frequency $=50 \%$

3. Acceptable error $=10 \%$

4. Confidence coefficient $=99 \%$

5. Minimum sample size $=103$

The inclusion criteria had been decided for the current study as those professionals and technical nurses who are working in the selected settings, with minimum of one-year experience and available through data collection period and welling to participate in the study.

\subsubsection{Tool of the Study (Instrument)}

The researchers used self-administered questionnaires to collect the study's data. The questionnaire package used in this study consisted of three main scales as well as a demographic data sheet. The scales were namely: Cyberloafing scale, Procrastination scale, and Conscientiousness scale. In the following sections, the instruments used in the study are described in detail with scaling, reliability, and validity estimates reported.

I. Instrument 1:

Cyberloafing instrument that is adapted by the researchers from Vitak et al [60] who measured cyberloafing using two different parts. The first part is Cyberloafing Variety which discusses the activities that are done while using the internet e.g. sending emails, using online social or professional network like facebook or linkedin. Participants were asked to determine whether they engaged in each activity at home only, at work only, at home and work or neither. The second part is Cyberloafing frequency in which participants were asked to rate the frequency with which they engage in activities for personal reasons at work. Responses ranged from never $=0$ to several times a day $=5$.

\section{Instrument 2:}

Procrastination instrument adapted by researchers from Lay's [43] work which was called "General Procrastination Scale" containing 20 items that measures procrastination as a personality trait. For each item, responses ranged from "extremely uncharacteristic" (1) to "extremely characteristic" (5). Ten items were reversed-keyed where $(1=5,2=4,3=$ 3 ). Responses were then summed showing that the higher the 
score, the greater the procrastination behavior.

III. Instrument 3:

Conscientiousness instrument was adapted by researchers from the International Personality Item Pool [61] (IPIP, 2014) in which participants were asked to rate their behaviors against behavior description statements. The instrument consisted of 20 items and response were on five point likert scale ranged from "very inaccurate" to "very accurate". Nine items were reversed keyed out of the 20. Responses were summed with a higher score indicating a greater level of conscientiousness.

IV. Demographic data sheet:

The personal background questionnaire asked nurses to fill their responses in a set of selected personal information including; Sex, age, nationality, and work related information including pattern of working, Number of working hours...etc.

\subsection{Methods of Data Collection}

1. Permission to conduct the study was obtained from the Dean of the Faculty of Nursing, Damanhour University and from the director and the nursing director of Damanhour National Medical Institute.

2. Instruments were translated into Arabic language by the researchers to suit its utilization in Egyptian culture, and to assure consistency among study participants, questionnaires were submitted to them in the Arabic language.

\subsubsection{Validity of the Instruments}

Two bilingual academic professional revised the translated study tool. A back-translation was conducted by the researcher and revised by another bilingual translator to assure that the translated statements retained the same meanings. To establish content validity, the questionnaire was submitted to a jury composed of five experts affiliated to different universities but all are Nursing Administration professors to prove the relevance of questionnaire statements to the study objectives.

Based on the feedback, some modifications were done on the questionnaire to be more compatible with Egyptian culture.

1. Reliability of the Arabic version of the instruments was done using Cronbach's alpha for the three instruments; Cyberloafing instrument $=0.965$, Procrastination instrument $=0.897$ and Conscientiousness instrument $=$ 0.755

2. A pilot study was carried out on approximately $10 \%$ of the sample $(\mathrm{N}=27)$ who were excluded from the study subjects. The pilot study was done to test facility, clarity and applicability of the instrument. Accordingly, the necessary modifications were done.

3. Instrument was distributed for initial data collection to participants in previously mentioned hospitals' units after explaining the purpose of the study.

4. The researchers explained the aim of the study to the nurses and take their consent before distribution of the questionnaire.
5. The data collection started on 1st of August 2017 and ended on 30th of September 2017.

6. The questionnaire was distributed then recollected either in the same day or one day later.

\subsubsection{Ethical Considerations}

An informed consent was obtained from all nurses in all units after explanation of the aims of the study before distributing the study's instrument.

Confidentiality, anonymity and privacy were assured.

Participants were notified that they are free to withdraw at any time without any drawbacks.

\subsubsection{Statistical Analysis of the Data}

Data were fed to the computer and analyzed using IBM SPSS software package version 20.0. Qualitative data were described using number and percent. The KolmogorovSmirnov test was used to verify the normality of distribution Quantitative data were described using mean, standard deviation. Significance of the obtained results was judged at the $5 \%$ level.

The used tests were

1. Chi-square test

For categorical variables, to compare between different groups

2. Fisher's Exact or Monte Carlo correction

Correction for chi-square when more than $20 \%$ of the cells have expected count less than

3. Mann Whitney test

For abnormally distributed quantitative variables, to compare between two studied groups

4. Kruskal Wallis test

For abnormally distributed quantitative variables, to compare between more than two studied groups

5. Spearman coefficient

To correlate between two distributed abnormally quantitative variables

\section{Results}

This section presents demographic variables and results of the descriptive and inferential statistical analyses of the named variables. Results are presented for each research question. The main variables that were measured in this study included Cyberloafing variety, Cyberloafing Frequency, Procrastination, and Conscientiousness

The current study aims to determine the relationship between cyberloafing, procrastination and conscientiousness among staff nurses working in Damanhour National Medical Institute.

Research Questions:

1. What is the frequency, variety of cyberloafing among study subjects?

2. What is the procrastination level among study subjects?

3 . What is the level of conscientiousness among nurses?

4. Is there a relationship between cyberloafing, procrastination and conscientiousness among nurses according to their demographic characteristics? 
Table 1. Distribution of the overall study subjects according to their demographic data $(n=157)$.

\begin{tabular}{|c|c|c|c|}
\hline & & No. & $\%$ \\
\hline \multirow{3}{*}{1.1} & Access to internet during working hrs: & & \\
\hline & No & 88 & 56.1 \\
\hline & Yes & 69 & 43.9 \\
\hline \multirow{4}{*}{1.2} & Sex: & & \\
\hline & Male & 40 & 25.5 \\
\hline & Female & 117 & 74.5 \\
\hline & Age (years): & & \\
\hline \multirow{3}{*}{1.3} & $20<35$ & 72 & 45.9 \\
\hline & $35<45$ & 64 & 40.8 \\
\hline & $45<60$ & 21 & 13.4 \\
\hline \multirow{3}{*}{1.6} & Pattern of working time & & \\
\hline & Full time & 107 & 68.2 \\
\hline & Part time & 50 & 31.8 \\
\hline \multirow{3}{*}{1.7} & Working hours per week & & \\
\hline & $10<20$ & 50 & 31.8 \\
\hline & $40<45$ & 107 & 68.2 \\
\hline \multirow{3}{*}{1.8} & Hold a managerial position & & \\
\hline & No & 108 & 68.8 \\
\hline & Yes & 49 & 31.2 \\
\hline
\end{tabular}

It could be seen from table 1 which shows the demographic distribution of participants that (56.1\%) of nurses didn't have access to the internet during working hours. About two third of the study sample (74.1\%) were female nurses and (54.9\%) aged from 20 to less than 35 .
Also, $(68.2 \%)$ were working in full time working pattern and were working from 40 to less than 45 hours per week. In addition to $(68.8 \%)$ of nurses were not holding a leadership position.

Table 2. Spearman's correlation between cyberloafing variety, frequency, procrastination and conscientiousness $(n=157)$.

\begin{tabular}{|c|c|c|c|c|c|}
\hline Variables & & Cyberloafing variety & Cyberloafing Frequency & Procrastination & Conscientiousness \\
\hline \multirow{2}{*}{ Cyberloafing variety } & $r_{\mathrm{s}}$ & & $0.528^{*}$ & $0.259^{*}$ & $0.341^{*}$ \\
\hline & $\mathrm{p}$ & & $<0.001^{*}$ & $<0.001^{*}$ & $<0.001^{*}$ \\
\hline \multirow{2}{*}{ Cyberloafing Frequency } & $\mathrm{r}_{\mathrm{s}}$ & & & $-0.389^{*}$ & $0.158^{*}$ \\
\hline & $\mathrm{p}$ & & & $<0.001^{*}$ & $0.048^{*}$ \\
\hline \multirow{2}{*}{ Procrastination } & $\mathrm{r}_{\mathrm{s}}$ & & & & $0.488^{*}$ \\
\hline & $\mathrm{p}$ & & & & $<0.001^{*}$ \\
\hline Conscientiousness & $\mathrm{p}$ & & & & \\
\hline
\end{tabular}

$\mathrm{r}_{\mathrm{s}}$ : Spearman coefficient

*: Statistically significant at $\mathrm{p} \leq 0.05$

It could be observed from table 2 that there are significant correlations between cyberloafing variety and cyberloafing frequency, procrastination and conscientiousness where $\mathrm{p}=$ $<0.001$ for the three variables respectively. Regarding, cyberloafing frequency, a negative significant correlation was found with procrastination where $\mathrm{p}=<0.001$ and a positive significant correlation with conscientiousness where $\mathrm{p}=0.048$. Another positive significant correlation was found between procrastination and conscientiousness in which $\mathrm{p}=<0.001$.

Table 3. Descriptive analysis of the studied nurses according to cyberloafing variety, frequency, procrastination and conscientiousness.

\begin{tabular}{lll}
\hline Percent score of study variables & Min. - Max. & Mean \pm SD. \\
\hline Cyberloafing Variety & $0.0-44.4$ & $5.67 \pm 14.87$ \\
Cyberloafing Frequency & $0.0-37.50$ & $13.81 \pm 15.08$ \\
Procrastination & $48.75-56.25$ & $51.86 \pm 2.84$ \\
Conscientiousness & $55.0-73.75$ & $61.64 \pm 7.51$ \\
\hline
\end{tabular}

Table 3 illustrates the descriptive statistics of studied subjects in relation to cyberloafing variety, frequency, procrastination and conscientiousness. It could be noticed from the table that the highest percent mean score was for conscientiousness $(61.64 \pm 7.51)$ while the lowest mean percent score was for cyberloafing variety $(5.67 \pm 14.87)$.

Table 4. Distribution of the studied nurses according to their daily practices toward using technology in work. $(n=157)$.

\begin{tabular}{lll}
\hline Using technology in work & No. & \% \\
\hline $\begin{array}{l}\text { Total hours working on PC } \\
\text { Less than 10 }\end{array}$ & 157 & 100.0 \\
Using smart phone at work & 138 & 87.9 \\
Never & 19 & 12.1 \\
Once daily & & \\
Policy for internet use & 88 & 56.1 \\
Don't know & 69 & 43.9 \\
No & & \\
You are aware of the policy & 157 & 100.0 \\
Not aware & & \\
\hline
\end{tabular}

Table 4 shows the distribution of the nurses according to 
their work practices toward using technology. It could be seen that all study sample used the personal computer less than 10 hours and $(87.9 \%)$ never used smart phone at work, while (12.1\%) used it once daily. Also, (56.1\%) didn't know whether there is a policy for controlling using internet at the hospital where they are working or not. Also, all studied sample were not aware about the presence of policy regarding using internet.

Table 5. Relation between participants' sex and Cyberloafing variety, Frequency, Procrastination and Conscientiousness.

\begin{tabular}{|c|c|c|c|c|}
\hline \multirow{3}{*}{ Variables } & \multicolumn{2}{|l|}{ Sex } & \multirow{3}{*}{$\mathbf{U}$} & \multirow{3}{*}{$\mathbf{p}$} \\
\hline & Male $(n=40)$ & Female $(n=117)$ & & \\
\hline & Mean $\% \pm$ SD & Mean $\% \pm$ SD & & \\
\hline Cyberloafing variety & $0.0 \pm 0.0$ & $7.60 \pm 16.80$ & $1940.0^{*}$ & $0.005^{*}$ \\
\hline Cyberloafing Frequency & $0.0 \pm 0.0$ & $18.54 \pm 14.75$ & $580.0^{*}$ & $<0.001^{*}$ \\
\hline Procrastination & $51.31 \pm 1.26$ & $52.05 \pm 3.18$ & 2282.5 & 0.812 \\
\hline Conscientiousness & $55.78 \pm 0.93$ & $63.64 \pm 7.72$ & $800.0^{*}$ & $<0.001^{*}$ \\
\hline
\end{tabular}

$\mathrm{U}$ : Mann Whitney test *: Statistically significant at $\mathrm{p} \leq 0.05$

Table 5 shows the relation between participants' sex and different study's variables. It could be noticed that in relation to cyberloafing variety female had a mean percent score (7.60 \pm 16.80$)$ higher than male with a significant difference $(\mathrm{p}=0.005)$. Regarding cyberloafing frequency again female scored higher than male with significant difference in which $(p=<0.001)$. For conscientiousness there was a significant difference between female and male $(\mathrm{p}=<0.001)$ and female scored higher $(63.64 \pm 7.72)$ than male.

Table 6. Relation between leadership position with Cyberloafing variety and Frequency.

\begin{tabular}{|c|c|c|c|c|}
\hline \multirow{3}{*}{ Percent score } & \multicolumn{2}{|c|}{ Leadership position } & \multirow{3}{*}{$\mathbf{U}$} & \multirow{3}{*}{$\mathbf{p}$} \\
\hline & No $(n=108)$ & Yes $(n=49)$ & & \\
\hline & Mean $\% \pm$ SD & Mean $\% \pm$ SD & & \\
\hline Cyberloafing variety & $0.0 \pm 0.0$ & $18.14 \pm 22.07$ & $1556.0^{*}$ & $<0.001^{*}$ \\
\hline Cyberloafing Frequency & $13.14 \pm 13.21$ & $15.31 \pm 18.62$ & 2550.0 & 0.700 \\
\hline
\end{tabular}

U: Mann Whitney test

*: Statistically significant at $\mathrm{p} \leq 0.05$

Table 6 denotes the relation between participants holding leadership position with cyberloafing variety and frequency. It could be observed that for both cyberloafing variety and frequency, those who hold leadership position scored higher (18.14 \pm $22.07,15.31 \pm 18.62)$ respectively than those who didn't. Only in cyberloafing variety those who hold leadership position differed significantly from those who didn't where $(p=<0.001)$.

Table 7. Relation between participants' age with Cyberloafing variety and Frequency.

\begin{tabular}{|c|c|c|c|c|c|}
\hline \multirow{3}{*}{ Variables } & \multicolumn{3}{|l|}{ Age (years) } & \multirow{3}{*}{$\mathbf{H}$} & \multirow{3}{*}{$\mathbf{p}$} \\
\hline & $25<35(n=72)$ & $35<45(n=64)$ & $45<60(n=21)$ & & \\
\hline & Mean $\% \pm$ SD & Mean $\% \pm$ SD & Mean $\% \pm$ SD & & \\
\hline Cyberloafing variety & $0.0 \pm 0.0$ & $13.89 \pm 20.76$ & $0.0 \pm 0.0$ & $33.093^{*}$ & $<0.001^{*}$ \\
\hline Cyberloafing Frequency & $15.80 \pm 14.07$ & $16.11 \pm 16.32$ & $0.0 \pm 0.0$ & $25.587^{*}$ & $<0.001^{*}$ \\
\hline
\end{tabular}

$\mathrm{H}$ : H for Kruskal Wallis test

*: Statistically significant at $\mathrm{p} \leq 0.05$

Table 7 shows the relation between participants age categories with cyberloafing variety and frequency. It could be observed that for both cyberloafing variety and frequency, those who are aged from 35 to less thah 45 years scored higher $(13.89 \pm 20.76,16.11 \pm 16.32)$ respectively than other age groups. Also, cyberloafing variety and frequency differed significantly among age groups where $(p=<0.001)$

\section{Discussion}

Nowadays, as a consequence of very rapid emerging technologies especially the personal communication devices that are portable, available everywhere and connected to the internet, this leads to a huge concern among employers. Furthermore, in health care settings for these advanced devices to be available and attainable for health care providers, patients' safety and wellbeing are jeopardized by allowing nurses to carry and may be to use their cell phones in surfing internet in non-work related activities or to cyberloaf. The concern from employers has led to an explosion of research recently on cyberloafing' consequences, causes and nature [7, 62]. In this study, researchers are trying to determine cyberloafing's variety and frequency and to detect their relationship with procrastination, conscientiousness and certain demographic characteristics. Hence, there is little known about cyberlaofing generally and among nurses specifically. 
The current finding shows that there was a negative significant correlation between cyberloafing frequency and procrastination. This is an unexpected finding as with the increase of the time in which nurses use their personal devices to surf the internet, they reduce the procrastination. This could be attributed to that participants of the study are not using their cell phone frequently and this could be shown from the frequency mean score which is very low in comparison to other factors. This finding is contradicting with those of Woods [63] who found a positive non-significant relationship and referred this finding to the inconsistency of cyberloafing measures used in different previous studies and recommended to work more on the measures of cyberloafing. At the same line, Garrett and Daziger [64] stated that cyberloafing measures needs to be worked on to maintain the consistency of findings. In addition to what was stated by Piowtroski, who added that analysis of the literature showed less studies have been done in the area where personality traits are linked to cyberloafing [65].

On the other hand, a positive significant correlation was detected between cyberloafing frequency and conscientiousness. This is another unanticipated finding as the more times nurses are cyberloafing, the more conscientious they are. However, the current study showed that nurses used their cell phone very little and this is normal because they are not using the internet in any of their work activities and they do not have personal computers neither in the units nor in Damanhour National Medical Institute generally, which really make them not cyberloafing frequently. Another positive significant correlation was found between procrastination and conscientiousness. This is may be because they are procrastinating but still alert and conscientious to the deadlines and the scheduled medication time. In this concern, Choi and Moran (2009) [66] found a form of active procrastination that does have desirable outcomes. They posit that active procrastinators make intentional decisions to procrastinate, using their strong motivation under time pressure, and are able to complete tasks before deadlines and achieve satisfactory outcomes. The same was found by Wood [63]. Another possible cause for this unexpected result could be the little number of research conducted on the workplace related procrastination rather than academic procrastination that had been searched extensively [67-70] At the same line, Freeman et al argued that researcher's knowledge about the mechanisms underlying procrastination remains limited [44]. This is an inconsistent result with those of Ferrari and Pychyl [42] who found a negative correlation between procrastination and conscientiousness. On the other hand, Choi and Moran found that conscientiousness did not have a significant correlation with procrastination [66].

The present study findings found that the highest percent mean score was for conscientiousness. This may be due to the nature of nurses' work that is based on caring and high conscientiousness as they are dealing with ill patients who are in need to them and this requires them to be highly vigilant, alert and conscientious. On the other hand, the lowest mean percent score was found to be recorded for cyberloafing variety. This is expected, as it could be seen during data collection that nurses working in Damanhour National Medical Institute are using very basic phones which are not connected to the internet and for messaging a person through SMS, this is considered an expensive way of communication. In this context, a report was issued by the Egyptian Ministry of Communication and Information Technology (2015) [71] which stated that the educational hospitals scored the highest percentage among different hospitals types using the internet and the private hospitals were the lowest in using it. Regarding cyberloafing variety, the most dominant internet activities in hospitals was sending and receiving e-mails and was in Egyptian hospitals among doctors, followed by getting information on medical apparatus, and finally medical information exchange with consultants during 2012 [5]. Unfortunately, no research till present measured cyberloafing variety among nurses in Egyptian health care settings.

The current study findings showed that gender differed significantly in cyberloafing variety, frequency and conscientiousness, where female scored higher than males. This result could be attributed to the fact that the current research studies the nursing profession, which is known in Egypt to be a more feminine profession than masculine one. The activities evaluated like shopping and sending (SMS) are well known to be female related activities. This finding in line with Lim et al. (2002) findings which showed Statistical differences in gender and cyberloafing between males and females, both in the frequency with which they chose to cyberloaf $(\mathrm{t}(86)=2.11, \mathrm{p}=.037)$, and in the types of cyberloafing activities in which they were likely to engage $(\mathrm{t}$ $(86)=2.32, p=.022)[21]$. While the current study finding is inconsistent with those of Jia et al (2013) who stated that male employees tend to cyberloaf more than female ones [72]. Moreover, Ozler and Polat (2012) found that the gender affected cyberloafing behaviors [7]. In the same line, Stavropoulos et al. (2013) stated that males tend to experience greater risk of Internet abuse [73]. In addition, Kumar et al claimed that males as consumers uses the internet for e-commerce activities more than females [74]. On the other hand, Weatherbee stated that more research are required to ensure the correlation between gender differences and cyberloafing frequency and activities [75].

The present study found that there is a significant relation between participants holding leadership position and cyberloafing variety denoting that those who hold leadership position differed significantly from those who did not. This could be a result of holding a senior position, which is considered stressful and may be people in these positions want to reduce the stress by surfing the internet. This result is emphasized by Davis et al. who stated that some people use the Internet to cope with stress. [31]

Another cause which was stated by Garrett and Danziger could be that senior professionals are highly paid and highly educated and are more autonomous in dealing with the internet in their workplaces [64]. The same was found by 
Ugrin et al. who reported that managers and seniors are more liable to cyberloafing than others [76].

Regarding participants' age, the current study results found that for both cyberloafing variety and frequency differed significantly among age groups where the older nurses are more prone to cyberloaf than younger ones. This could be attributed to the fact that those who are older in age are the same who are holding a senior position and feel more autonomous in dealing with the internet and using the personal communication devices freely than younger one. Also, may be this could be because of the older age nurses are more stressed in their work and need may be to off their mind by surfing the internet more frequently than younger one. Another cause, could be that the younger nurses are most probably those who are providing direct patient care and they are always with their patients rather than the older one who are usually occupied with administrative work in their offices. The same result was found by Restubog et al [77], while Ozler and Polat [7] found that no significant difference was found between age and cyberloafing behaviors. Other research found that younger employees are more prone to cyberloafing rather than older employee. [13]

On the other hand, many research found that neither age nor occupational status relate to employee's cyberloafing behavior [20, 78-79].

\section{Conclusion}

The study was conducted on 157 nurses both professional and technical. There were significant correlations between cyberloafing variety and cyberloafing frequency, procrastination and conscientiousness. A negative significant correlation was found between cyberloafing frequency and procrastination and a positive significant correlation with conscientiousness. Another positive significant correlation was found between procrastination and conscientiousness. Also, the study found that the highest percent mean score was for conscientiousness, while the lowest mean percent score was for cyberloafing variety. Only in cyberloafing variety those who hold leadership position differed significantly from those who didn't.

\section{Implications and Future Research Directions}

It is clear from previous research that cyberloafing is a topic of great interest to academics, health care field and businesses alike. The findings of the present study have gone some way in contributing to the literature on cyberloafing, procrastination and conscientiousness in the Nursing health care workplace. Nevertheless, future research may benefit from employing larger population samples from a wider variety of age and health care organizations. Moreover, a clearer definition of terms for cyberloafing and what constitutes cyberloafing behavior would be beneficial, as well as the use of empirically tested measures that assess cyberloafing in the workplace. Hence, that future studies in this area could benefit from a more empirical means of testing cyberloafing.

\section{Strengths and Limitations}

The present study has made a positive contribution to cyberloafing research in relation to procrastination and conscientiousness, as well as to the field of cyberloafing in nursing and, in Egypt, in particular.

Potential limitations of the current study were; overall generalizability of the current study findings was limited due to the study being limited to one setting. The crosssectional design precludes researches abilities to attribute strong causal effects; the results cannot be generalized for the whole. The use of self-report measures raises concerns about common method variance. Self-reporting will lead to social durability; respondents give answers, which are socially desired. The voluntary nature of the study is an additional limitation. This survey included only nurses that were accessible and willing to take part in the study. Respondents that filled out the survey might display behaviors that were a little different from others that did not complete the survey.

\section{References}

[1] Griffiths M. Internet abuse and internet addiction in the workplace. Journal of Workplace Learning. 2010 Sep 14; 22 (7): 463-72.

[2] Lim VK. The IT way of loafing on the job: Cyberloafing, neutralizing and organizational justice. Journal of Organizational Behavior: The International Journal of Industrial, Occupational and Organizational Psychology and Behavior. 2002 Aug; 23 (5): 675-94.

[3] Phillips JG, Reddie L. Decisional style and self-reported email use in the workplace. Computers in Human Behavior. 2007 Sep 1; 23 (5): 2414-28.

[4] Blanchard AL, Henle CA. Correlates of different forms of cyberloafing: The role of norms and external locus of control. Computers in Human Behavior. 2008 May 31; 24 (3): 106784.

[5] Lim VK, Teo TS. Prevalence, perceived seriousness, justification and regulation of cyberloafing in Singapore: An exploratory study. Information \& Management. 2005 Dec 31; 42 (8): 1081-93.

[6] Piotrowski C. Cyberloafing: A content analysis of the emerging literature. Journal of Instructional Psychology. 2012 Sep 1; 39 (3/4): 259.

[7] Ozler DE, Polat G. Cyberloafing phenomenon in organizations: Determinants and impacts. International Journal of eBusiness and eGovernment Studies. 2012 Dec 1; 4 (2): $1-5$.

[8] Garrett RK, Danziger JN. On cyberslacking: Workplace status and personal Internet use at work. CyberPsychology \& Behavior. 2008 Jun 1; 11 (3): 287-92. 
[9] Ugrin JC, Pearson JM, Odom MD. Cyber-slacking: Selfcontrol, prior behavior and the impact of deterrence measures. Review of Business Information Systems (RBIS). 2011 May 31; 12 (1): 75-88.

[10] Baumgart DC. Smartphones in clinical practice, medical education, and research. Archives of internal medicine. 2011 Jul 25; 171 (14): 1294-6.

[11] Divall P, Camosso-Stefinovic J, Baker R. The use of personal digital assistants in clinical decision making by health care professionals: a systematic review. Health informatics journal. 2013 Mar; 19 (1): 16-28.

[12] Yeung MS, Lapinsky SE, Granton JT, Doran DM, Cafazzo JA. Examining nursing vital signs documentation workflow: barriers and opportunities in general internal medicine units. Journal of clinical nursing. 2012 Apr 1; 21 (7-8): 975-82.

[13] Shepherd JD, Badger-Brown KM, Legassic MS, Walia S, Wolfe DL. SCI-U: E-learning for patient education in spinal cord injury rehabilitation. The journal of spinal cord medicine. 2012 Sep 1; 35 (5): 319-29.

[14] Elias BL, Fogger SA, McGuinness TM, D'Alessandro KR. Mobile apps for psychiatric nurses. Journal of psychosocial nursing and mental health services. 2013 Dec 4; 52 (4): 42-7.

[15] Sohn W, Shreim S, Yoon R, Huynh VB, Dash A, Clayman R, Lee HJ. Endockscope: using mobile technology to create global point of service endoscopy. Journal of endourology. 2013 Sep 1; 27 (9): 1154-60.

[16] Zuo KJ, Guo D, Rao J. Mobile teledermatology: a promising future in clinical practice. Journal of cutaneous medicine and surgery. 2013 Nov; 17 (6): 387-91.

[17] Nasar JL, Troyer D. Pedestrian injuries due to mobile phone use in public places. Accident Analysis \& Prevention. 2013 Aug 31; 57: 91-5.

[18] Wu RC, Lo V, Morra D, Wong BM, Sargeant R, Locke K, Cavalcanti R, Quan SD, Rossos P, Tran K, Cheung M. The intended and unintended consequences of communication systems on general internal medicine inpatient care delivery: a prospective observational case study of five teaching hospitals. Journal of the American Medical Informatics Association. 2013 Jan 25; 20 (4): 766-77.

[19] Black E, Light J, Black NP, Thompson L. Online social network use by health care providers in a high traffic patient care environment. Journal of medical Internet research. 2013 May; 15 (5).

[20] Coker BL. Freedom to surf: the positive effects of workplace Internet leisure browsing. New Technology, Work and Employment. 2011 Nov 1; 26 (3): 238-47.

[21] Lim VK, Chen DJ. Cyberloafing at the workplace: gain or drain on work?. Behaviour \& Information Technology. 2012 Apr 1; 31 (4): 343-53.

[22] Prasad S, Lim VK, Chen DJ. Self-Regulation, Individual Characteristics and Cyberloafing. InPACIS 2010 Jul 9 (p. 159).

[23] Ozdalga E, Ozdalga A, Ahuja N. The smartphone in medicine: a review of current and potential use among physicians and students. Journal of medical Internet research. 2012 Sep; 14 (5).
[24] Patterson P. Smartphones, tablets in the OR: with benefits come distractions. OR manager. 2012 Apr; 28 (4): 1-6.

[25] Emergency Care Research Institute (ECRI). Top 10 health technology hazards for 2014. Health Dev. 2013; 42 (11). Available at:

https://www.ecri.org/Resources/Whitepapers_and_reports/ 2014_Top_10_Hazards_Executive_Brief.pdf Retrieved Feb 2019 .

[26] American Association of Nurse Anesthetists [AANA]. Mobile Device Use, Position statement number 2.18. Park Ridge, IL: American Association of Nurse Anesthetists. (2013) Available at: https://www.aana.com/docs/default-source/practice-aanacom-web-documents-(all)/mobile-informationtechnology.pdf?sfvrsn=610049b1_2, Retrieved Feb 2019

[27] Prinz, A. (2011). Professional social networking for nurses. American Nurse Today, 6 (7). Retrieved from www.americannursetoday.com/article $\cdot$ asp $x$ ? $\mathrm{id}=8016 \& \mathrm{fid}=$

[28] Fraser, R. (2011). The Nurse's Social Media Advantage: How Making Connections and Sharing Ideas Can Enhance Your Nursing Practice. Indianapolis, IN: Sigma Theta Tau.

[29] Royal College of Nursing. (2009). Legal advice for RCN members using the Internet. Retrieved from www.rcn.org.uk/_data/assets/pdf_file/0008/272195/003557.p df

[30] Anderson, J. \& Puckrin, K. (2011). Social network use: A test of self-regulation. Journal of Nursing Regulation, 2 (1), 36-41.

[31] Davis, R., Flett, G. L., \& Besser, A. (2002). Validation of a New Scale for Measuring Problematic Internet Use: Implications for Pre-employment Screening. Cyberpsychology Behavior, 5 (4), pp. 331- 345.

[32] O., Reinecke, L., Schmutzer, G., Stark, B., Wölfling, K., 2016. Procrastination, distress and life satisfaction across the Age Range - A German Representative Community Study. PLoS One 11, e0148054. http://dx.doi.org/10.1371/journal.pone.0148054.

[33] Billieux J, Chanal J, Khazaal Y, Rochat L, Gay P, Zullino D, Van der Linden M. Psychological predictors of problematic involvement in massively multiplayer online role-playing games: illustration in a sample of male cybercafe players. Psychopathology. 2011; 44 (3): 165-71.

[34] Gentile DA, Choo H, Liau A, Sim T, Li D, Fung D, Khoo A. Pathological video game use among youths: a two-year longitudinal study. Pediatrics. 2011 Jan 12: peds-2010. http://dx.doi.org/10.1542/peds.2010-1353.

[35] Giannakos MN, Chorianopoulos K, Giotopoulos K, Vlamos P. Using Facebook out of habit. Behaviour \& Information Technology. 2013 Jun 1; $32 \quad$ (6): 594-602. http://dx.doi.org/10.1080/0144929X.2012.659218.

[36] The Ottawa Citizen (2008). Procrastination a personality trait. You're sitting at your desk, and you've got work to do. from Canada.com website: http://www.canada.com/ottawacitizen/news/city/story.html?id $=4 \mathrm{ca} 892 \mathrm{ae}-5 \mathrm{ebd}-411 \mathrm{~b}-96 \mathrm{bd}-75163 \mathrm{f} 6 \mathrm{c} 6 \mathrm{f} 4 \mathrm{~d}$.

[37] Steel P. Arousal, avoidant and decisional procrastinators: Do they exist?. Personality and Individual Differences. 2010 Jun 1; 48 (8): 926-34. 
[38] Akinsola MK, Tella A, Tella A. Correlates of academic procrastination and mathematics achievement of university undergraduate students. Eurasia Journal of Mathematics, Science \& Technology Education. 2007 Nov 1; 3 (4): 363-70.

[39] Chun Chu AH, Choi JN. Rethinking procrastination: Positive effects of" active" procrastination behavior on attitudes and performance. The Journal of social psychology. 2005 Jun 1; 145 (3): 245-64.

[40] Sirois FM, Kitner R. Less adaptive or more maladaptive? A meta-analytic investigation of procrastination and coping. European Journal of Personality. 2015 Jul; 29 (4): 433-44. https://doi.org/10.1002/per.1985.

[41] Kim KR, Seo EH. The relationship between procrastination and academic performance: A meta-analysis. Personality and Individual Differences. 2015 Aug 1; 82: 26-33. https://doi.org/10.1016/j.paid.2015.02.038.

[42] Ferrari JR, Doroszko E, Joseph N. Exploring procrastination in corporate settings: Sex, status, and settings for arousal and avoidance types. Individual Differences Research. 2005 Aug $1 ; 3(2): 140-9$.

[43] Lay CH. At last, my research article on procrastination. Journal of research in personality. 1986 Dec 1; 20 (4): 47495.

[44] Freeman EK, Cox-Fuenzalida LE, Stoltenberg I. Extraversion and arousal procrastination: Waiting for the kicks. Current Psychology. 2011 Dec 1; 30 (4): 375-82.

[45] Steel P. The nature of procrastination: A meta-analytic and theoretical review of quintessential self-regulatory failure. Psychological bulletin. 2007 Jan; 133 (1): 65.

[46] Ferrari JR, Pychyl TA. "If I Wait, My Partner Will Do It:" The Role of Conscientiousness as a Mediator in the Relation of Academic Procrastination and Perceived Social Loafing. North American Journal of Psychology. 2012 Mar 1; 14 (1). $13-24$.

[47] Chapman BP. Bandwidth and fidelity on the NEO-five factor inventory: replicability and reliability of item cluster subcomponents. Journal of Personality Assessment. 2007 Mar $27 ; 88$ (2): 220-34.

[48] Ehrenberg A, Juckes S, White KM, Walsh SP. Personality and self-esteem as predictors of young people's technology use. Cyberpsychology \& behavior. 2008 Dec 1; 11 (6): 739-41.

[49] Jackson JJ, Bogg T, Walton KE, Wood D, Harms PD, LodiSmith J, Edmonds GW, Roberts BW. Not all conscientiousness scales change alike: A multimethod, multisample study of age differences in the facets of conscientiousness. Journal of personality and social psychology. 2009 Feb; 96 (2): 446.

[50] Artistico D, Rothenberg AM. Assessing strengths and weaknesses in solving work problems: A Knowledge and Appraisal Personality Architecture (KAPA) analysis of the trait conscientiousness and self-efficacy. International Journal of Psychological Studies. 2013 Aug 6; 5 (3): 84.

[51] Neal A, Yeo G, Koy A, Xiao T. Predicting the form and direction of work role performance from the Big 5 model of personality traits. Journal of Organizational Behavior. 2012 Feb; 33 (2): 175-92.

[52] Westerman JW, Simmons BL. The effects of work environment on the personality-performance relationship: An exploratory study. Journal of Managerial Issues. 2007 Jul 1: 288-305.

[53] Griffin MA, Neal A, Parker SK. A new model of work role performance: Positive behavior in uncertain and interdependent contexts. Academy of management journal. 2007 Apr 1; 50 (2): 327-47.

[54] Chang HY, Shyu YI, Wong MK, Chu TL, Lam SM, Teng CI. Human Resource Strategies for Nurses: The Positive Impact of Conscientiousness and Neuroticism on Patient Safety. Journal of Trademarks.. 2018 Jun 1; 10 (2): 151-68.

[55] Lamb C, Babenko-Mould Y, Evans M, Wong CA, Kirkwood KW. Conscientious objection and nurses: Results of an interpretive phenomenological study. Nursing ethics. 2018 Jan 1: 0969733018763996.

[56] Lamb C, Evans M, Babenko-Mould Y, Wong C, Kirkwood K. Nurses' use of conscientious objection and the implications for conscience. Journal of advanced nursing. 2018 Oct 16.

[57] Fleming V, Ramsayer B, Zakšek TŠ. Freedom of conscience in Europe? An analysis of three cases of midwives with conscientious objection to abortion. Journal of medical ethics. 2018 Feb 1; 44 (2): 104-8.

[58] Dudley NM, Orvis KA, Lebiecki JE, Cortina JM. A metaanalytic investigation of conscientiousness in the prediction of job performance: Examining the intercorrelations and the incremental validity of narrow traits. Journal of Applied Psychology. 2006 Jan; 91 (1): 40.

[59] Mashi MS, Salimon MG. Consideration of future consequences as an antecedent of employee cyberloafing behavior among selected working adults in Nigeria. International Journal of Business and Technopreneurship. 2016; 6 (2): 319-34.

[60] Vitak J, Crouse J, LaRose R. Personal Internet use at work: Understanding cyberslacking. Computers in Human Behavior. 2011 Sep 1; 27 (5): 1751-9.

[61] The Items in the 45 Preliminary IPIP Scales Measuring the 45 AB5C Facets. Available at: https://ipip.ori.org/newAB5CKey.htm\#Conscientiousness, Retrieved Feb 2019

[62] Zoghbi-Manrique-de-Lara P. Reconsidering the boundaries of the cyberloafing activity: the case of a university. Behaviour \& Information Technology. 2012 May 1; 31 (5): 469-79.

[63] Woods F. A study into the relationship between cyberloafing, procrastination and conscientiousness in the workplace. May $2014 . \quad$ Available at https://esource.dbs.ie/bitstream/handle/10788/2074/hdip_woo ds_f_2014.pdf?sequence=1, Accessed on 6 January 2019.

[64] Garrett RK, Danziger JN. Disaffection or expected outcomes: Understanding personal Internet use during work. Journal of Computer-Mediated Communication. 2008 Jul 1; 13 (4): 93758.

[65] Piotrowski C. Counterproductive work behavior: Topical domain in emergent research. Journal of Instructional Psychology. 2013 Sep 1; 40 (3): 78.

[66] Choi JN, Moran SV. Why not procrastinate? Development and validation of a new active procrastination scale. The Journal of social psychology. 2009 Apr 1; 149 (2): 195-212. 
[67] Schödl MM, Raz A, Kluger AN. On the Positive Side of Avoidance Motivation: An Increase in Avoidance Motivation Reduces Procrastination among Students. Applied Psychology. 2018 Oct; 67 (4): 655-85.

[68] Codina N, Valenzuela R, Pestana JV, Gonzalez-Conde J. Relations between student procrastination and teaching styles: autonomy-supportive and controlling. Frontiers in psychology. $2018 ; 9$.

[69] Martinčeková L, Enright RD. The effects of self-forgiveness and shame-proneness on procrastination: exploring the mediating role of affect. Current Psychology. 2018: 1-0.

[70] Zhang Y, Dong S, Fang W, Chai X, Mei J, Fan X. Selfefficacy for self-regulation and fear of failure as mediators between self-esteem and academic procrastination among undergraduates in health professions. Advances in Health Sciences Education. 2018 May 29: 1-4.

[71] Ministry of Communication and Information Technology. Measuring the Digital Society in Egypt: Internet at a glance. Statistical Profile. (2015). Available at http://www.mcit.gov.eg/Upcont/Documents/Publications 127 2015000_Measuring_the_Digital_Society_in_Egypt_12_.pdf Accessed on 8 January 2019.

[72] Jia H, Jia R, Karau S. Cyberloafing and personality: The impact of the Big Five traits and workplace situational factors. Journal of Leadership \& Organizational Studies. 2013 Aug; 20 (3): $358-65$

[73] Stavropoulos V, Alexandraki K, Motti-Stefanidi F. Flow and telepresence contributing to Internet abuse: Differences according to gender and age. Computers in Human Behavior. 2013 Sep 1; 29 (5): 1941-8.
[74] Kumar M, Govindarajo NS. Malaysian Y generation consumer research: Does gender and technology literacy affirmative towards e-commerce activities? Journal of Economics and Behavioral Studies. 2014; 6 (12): 906-18.

[75] Weatherbee T G. Counterproductive use of technology at work: Information \& communications technologies and cyberdeviancy. Human Resource Management Review, 2009; 20 (1): 35-44.

[76] Ugrin JC, Pearson JM, Odom MD. Profiling cyber-slackers in the workplace: Demographic, cultural, and workplace factors. Journal of Internet Commerce. 2008 Oct 8; 6 (3): 75-89.

[77] Restubog SL, Garcia PR, Toledano LS, Amarnani RK, Tolentino LR, Tang RL. Yielding to (cyber)-temptation: Exploring the buffering role of self-control in the relationship between organizational justice and cyberloafing behavior in the workplace. Journal of Research in Personality. 2011 Apr 1; 45 (2): $247-51$.

[78] Black E, Light J, Black NP, Thompson L. Online social network use by health care providers in a high traffic patient care environment. Journal of medical Internet research. 2013 May; 15 (5).

[79] Ozdalga E, Ozdalga A, Ahuja N. The smartphone in medicine: a review of current and potential use among physicians and students. Journal of medical Internet research. 2012 Sep; 14 (5). 